\title{
LXXIV. Observations on chloric acid and the chlorates
}

\section{Lewis Thompson}

To cite this article: Lewis Thompson (1847) LXXIV. Observations on chloric acid and the chlorates, Philosophical Magazine Series 3, 31:211, 510-511, DOI: 10.1080/14786444708645897

To link to this article: http://dx.doi.org/10.1080/14786444708645897

册 Published online: 30 Apr 2009.

Submit your article to this journal

Џ Article views: 2

Q View related articles $\asymp$ 
refracting crust. This is, in itself, a very natural supposition, seeing that the fluid may have discharged its gaseous portion, and left behind it the matters which it held in solution. The cavities however, of this kind, which $I$ have described in a former paper, have no depolarizing action; and I find that those now under consideration have regular axes of double refraction. Hence the matter which covers them must be a regular crystalline shell, with optical and crystallographic axes-a phænomenon which has no parallel in mineralogy.

St. Leonard's College, St. Andrew's, February 15, 1845 .

LXXIV. Observations on Chloric Acid and the Chlorates. By Lewis Thompson.

To the Editors of the Philosophical Magazine and Journal. Gentremen,

$A \mathrm{~N}$ easy and ceconomical mode of preparing chloric acid and some of the chlorates has not been described in any chemical work that I am aware of: the following will be fonnd to answer extremely well.

Dissolve in two separate portions of boiling water one atom $(122.81)$ of chlorate of potash, and one atom (168.34) of bitartrate of ammonia; mix the two solutions together, and set the whole aside in order that the bitartrate of potash may crystallize; then mix the clear solution with an equal bulk of alcohol, and filter or pour off the alcoholic solution of chlorate of ammonia, which must now be boiled in a flask or other narrow-necked vessel, with an excess of recently-precipitated carbonate of baryta, until the ammonia is expelled, water being occasionally added; then filter the fluid, evaporate, and crystallize. In dissolving the chlorate of potash and bitartrate of ammonia, as little water must be used as possible.

The chlorates of strontia and lime may be prepared in a similar manner; and the metallic chlorates are easily prepareal by decomposing the chlorate of baryta by means of a sulphate of the base required.

Chloric acid is best obtained by dissolving a given weight of chlorate of baryta, and adding no more sulphuric acid than is sufficient to combine with the base; several hours or even days, however, appear necessary to effect this decomposition in the cold; after which the whole may be filtered and carefully evaporated at a low heat. When sulphuric acid is added to a solution of the chlorate of baryta, as long as it gives a precipitate, I have always found an excess of it in the chloric acid. 
The bitartrate of ammonia may be readily made by dissolving tartaric acid in water, saturating one-half of the solution with ammonia or its carbonate, and adding to this the remaining half of the liquid tartaric acid; the bitartrate of ammonia immediately precipitates.

For pyrotechnical purposes, the chlorates of baryta, strontia, lead, \&c. may be made without alcohol. With combustibles containing hydrogen, the chlorate of baryta produces a green flame of surpassing brilliancy; and the chlorate of strontia, although somewhat deliquescent, is much superior as a crimson to the nitrate of that earth.

$$
\begin{aligned}
& \text { I am, Gentlemen, } \\
& \text { Your most obedient Servant, } \\
& \text { Byker Bar, Newcastle-on-Tyne, } \\
& \text { October 14, 1847. }
\end{aligned}
$$

LXXV. On Quaternions; or on a Nerw System of Imaginaries in Algebra. By Sir William Rowan Hamiton, LL.D., V.P.R.I.A., F.R.A.S., Corresponding Member of the Institute of France, \&c., Andrewes' Professor of Astronomy in the University of Dublin, and Royal Astronomer of Ireland.

[Continued from p. 293.]

51. T has been shown* that if the two symbols,$x$ denote certain constant vectors, perpendicular to the two cyclic planes of an ellipsoid, and if $y, z$ denote two other and variable vectors, of which the former is normal to the ellipsoid at any proposed point upon its surface, while the latter is tangential to a line of curvature at that point, then the directions of these four vectors $r, x, y, \tau$ are so related to each other as to satisfy the condition $\uparrow$

$$
\text { S. } \nu \tau i \tau x=0 \text { (49.), article } 47 \text {; }
$$

$\mathrm{S}$ being the characteristic of the operation of taking the scalar part of a quaternion. And because the two latter of these four directions, namely the directions of the normal and tangential vectors $y$ and $\tau$, are always perpendicular to each other, this additional equation has been seen to hold good:

$$
\text { S. } v \tau=0 \text { (36.), article } 4.5 \text {. }
$$

Retaining the same significations of the symbols, and carrying forward for convenience the recent numbering of the formule,

* See the Philosophical Magazine for October 1847; or Proceedings of the Royal Irish Academy for July 1846.

+ Inadvertently transcribed as S. vick $=0$, towards the end of the last communication to this Magazine: but correctly printed in the formula (49.) here referred to. 